\title{
RUNG NHĨ VÀ NHỒI MÁU NÃO Ở BÊ̂NH NHÂN SAU VÁ THÔNG LIÊN NHĨ: VAI TRÒ CỦA PHẪU THUẬT MAZE
}

\section{TÓM TÁT}

Mặc dù là biến chứng thường gặp trong bệnh thông liên nhĩ (TLN) làm tăng nguy cơ nhồi máu não, rung nhĩ vẫn chưa được quan tâm một cách đầy đủ về diễn biến cũng như cách thức điều trị. Báo cáo ca bệnh 54 tuổi TLN lỗ thứ hai, rung nhĩ được phẫu thuật nội soi toàn bộ vá TLN, sửa van ba lá (VBL). Bệnh nhân xuất hiện nhồi máu não cấp do huyết khối gây tắc hoàn toàn đoạn 2 của động mạch não giữa bên trái ngày thứ 3 sau mổ. Bệnh nhân may mắn được can thiệp hút máu đông kịp thời và hồi phục hoàn toàn. Mục đích của bài báo nhằm phân tích để làm rõ vai trò và lợi ích của phẫu thuật Maze trong rung nhĩ ở bệnh nhân TLN.

Tù khóa: rung nhĩ, thông liên nhĩ, phẫu thuật Maze

\section{SUMMARY}

Atrial arrythmia was a usual complication in patients with atrial septal defect (ASD). Even though it was a risk factor for stroke, this condition was often not given adequate follow-up and treatment. We reported a clinical case of a 54-year-old patient with secundum ASD and atrial fibrillation. The patient was undergone totally endoscopic surgery for ASD closure and tricuspid annuloplasty. Stroke occurred at day 3 postoperatively, due to an obstructive thrombosis in the second segment of the left middle cerebral artery. Urgence percutaneous angioplasty was indicated and the patient was then fully recovered. The purpose of this report was to analyze the role and advantage of the Maze procedure in ASD patients with atrial fibrillation.

Keywords: atrial septal defect,atrial fibrillation, Maze procedure

\section{I. ĐặT VẤN ĐỀ}

Rối loạn nhịp nhĩ bao gồm: cuồng nhĩ và rung nhĩ là những biểu hiện thường gặp nhất ở những bệnh nhân thông liên nhĩ (TLN) trưởng thành. Chúng có thể để lại những di chứng nặng nề do biến chứng nhồi máu não, hoặc chí ít là những cơn thiếu máu não thoáng qua $[1,2]$. Thời gian gần đây đã có ngày càng nhiều nghiên cứu liên quan đến vấn đề này và đã có một số quan điểm được đưa ra về cách thức điều trị rối loạn nhịp nhĩ ở bệnh nhân TLN[3, 4]. Trong bài này, chúng tôi báo cáo một trường hợp sau mổ vá TLN bị biến chứng nhồi máu não do rung nhĩ; qua đó cập nhật kiến thức liên quan.

\section{BÁO CÁO CA BÊNH}

Bệnh nhân nữ 54 tuổi, vào viện vì khó thở và hồi hộp đánh trống ngực. Bệnh nhân có tim loạn nhịp hoàn toàn (không khai thác được tiền sử rối loạn nhịp), gan không to. Siêu âm tim qua thành ngực xác định chẩn đoán với TLN lỗ thứ hai lớn, shunt trái - phải, hở VBL nhiều, nhĩ trái $48 \mathrm{~mm}$, đường kính thất phải $46 \mathrm{~mm}$, tăng áp lực động mạch phổi (ĐMP) nặng $(85 \mathrm{mmHg})$. Sau khi can thiệp thất bại, bệnh nhân được phẫu thuật thành công bằng phương pháp phẫu thuật nội soi toàn bộ tim đập, không robot hỗ trợ đóng lỗ TLN sử dụng miếng vá nhân tạo, sửa VBL theo phương pháp DeVega cải tiến. Thời gian phẫu thuật và thời gian chạy máy lần lượt là 190 phút và 60 phút. Bệnh nhân hồi phục nhanh trong giai đoạn hồi sức: rút nội khí quản sau hơn 1 ngày, dẫn lưu không chảy máu, thời gian nằm hồi sức 2 ngày.

* Bệnh viện tim Hà Nội

** Trung tâm Tim mạch Bệnh viên E

Người chịu trách nhiệm khoa học: BS Đặng Quang Huy

Ngày nhận bài: 01/11/2019 - Ngày Cho Phép Đăng: 20/12/2019

Phản Biện Khoa học: PGS.TS. Đặng Ngọc Hùng GS.TS. Lê Ngoc Thành 


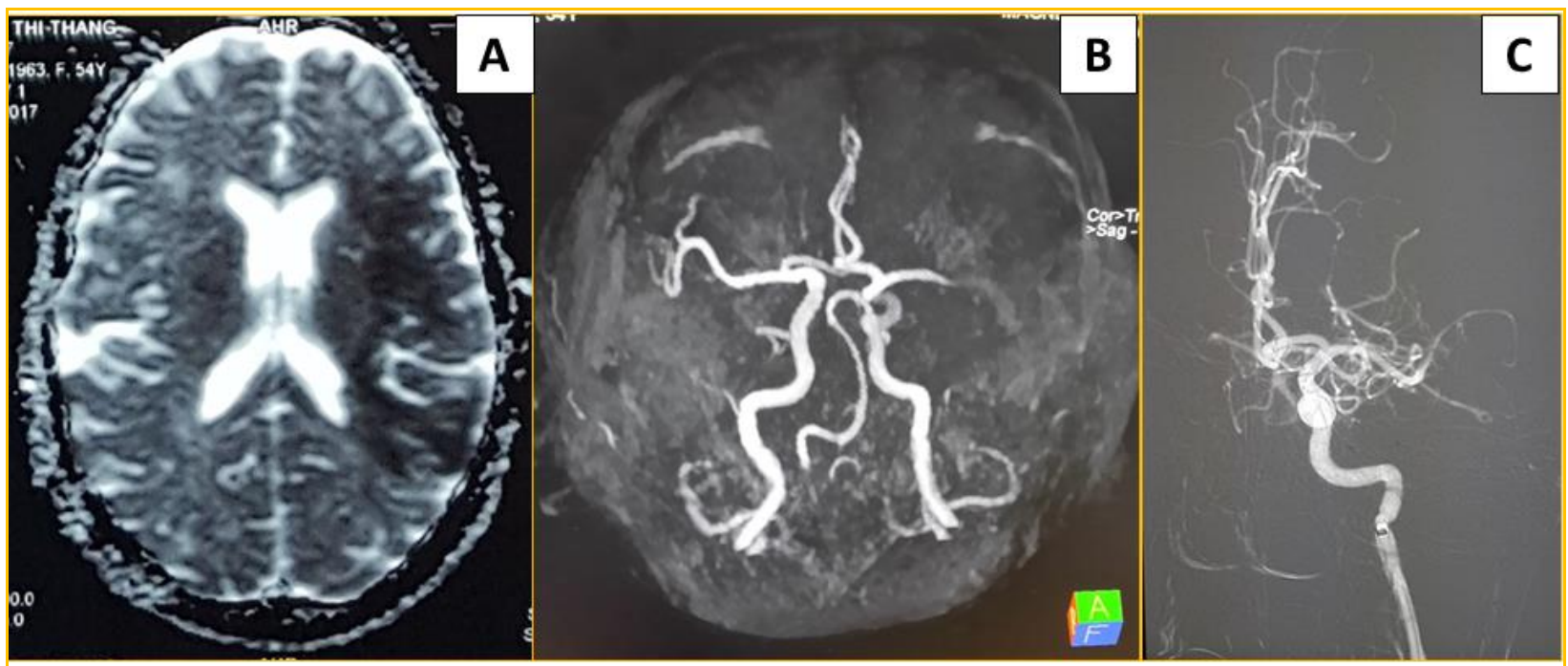

Hình 1. Kết quả chup cộng hưởng tù ngay sau khi bệnh nhân có triệu chứng. A, Hình ảnh thiếu máu não diện rộng vùng thái dưong - trán bên trái; $\boldsymbol{B}$ và $\boldsymbol{C}$, hình ảnh tắc hoàn toàn đoạn II của động mach não giũua bên trái

Ngày thứ 3 sau mổ, mặc dù đang duy trì từ thời điểm xuất hiện triệu chứng. Sau can thiệp thuốc chống đông Heparin đường tĩnh mạch, mạch máu não thông tốt (hình 2), bệnh nhân hồi bệnh nhân xuất hiện lơ mơ kèm dấu hiệu thần phục hoàn toàn (hình 3). Siêu âm tim sau mổ: lỗ kinh khu trú. MRI sọ não xác nhận chẩn đoán TLN vá kín, VBL còn hở nhẹ, áp lực ĐMP giảm nhồi máu não diện rộng thùy thái dương - trán nhiều $(29 \mathrm{mmHg})$. Bệnh nhân được ra viện duy trì bên trái giai đoạn tối cấp do tắc đoạn II của ĐM phác đồ chống đông kháng Vitamin $\mathrm{K}$; không có não giữa (hình 1). Bệnh nhân được can thiệp hút di chứng thần kinh sau mổ 1 năm. huyết khối, tái thông lại đoạn mạch tắc 3,5 giờ kể

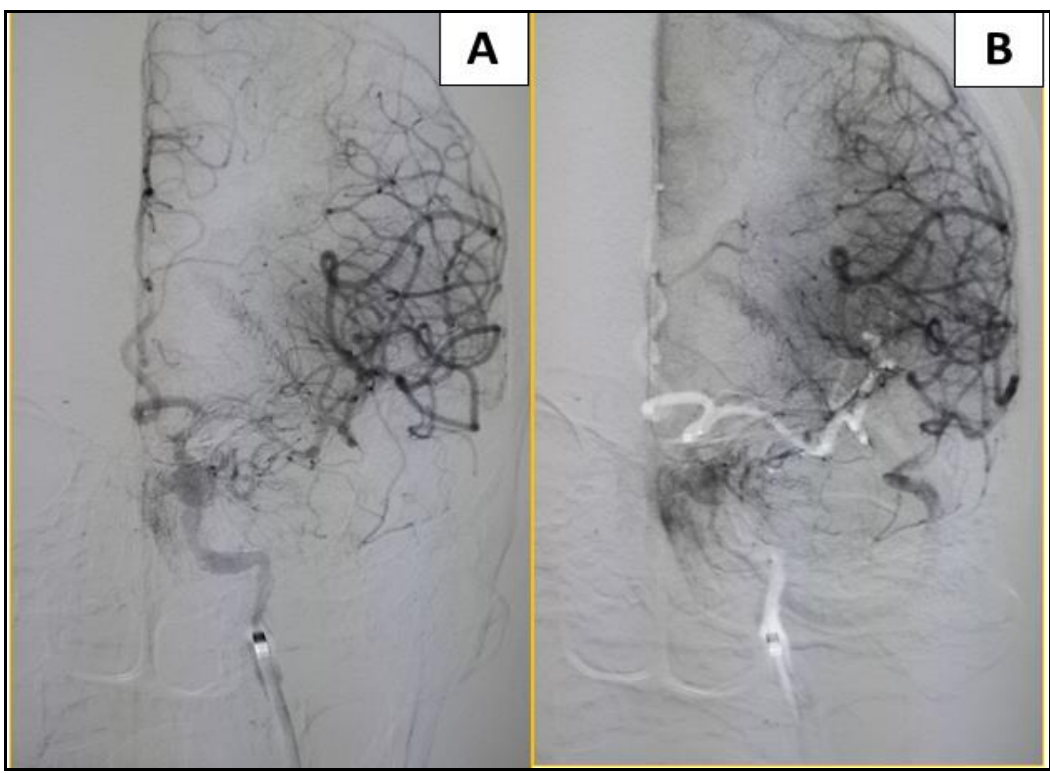

Hình 2. Hình ảnh sau khi đã tái thông động mạch não giũa bên trái.

$\boldsymbol{A}$, thì động mạch; $\boldsymbol{B}$, thì tĩnh mạch 


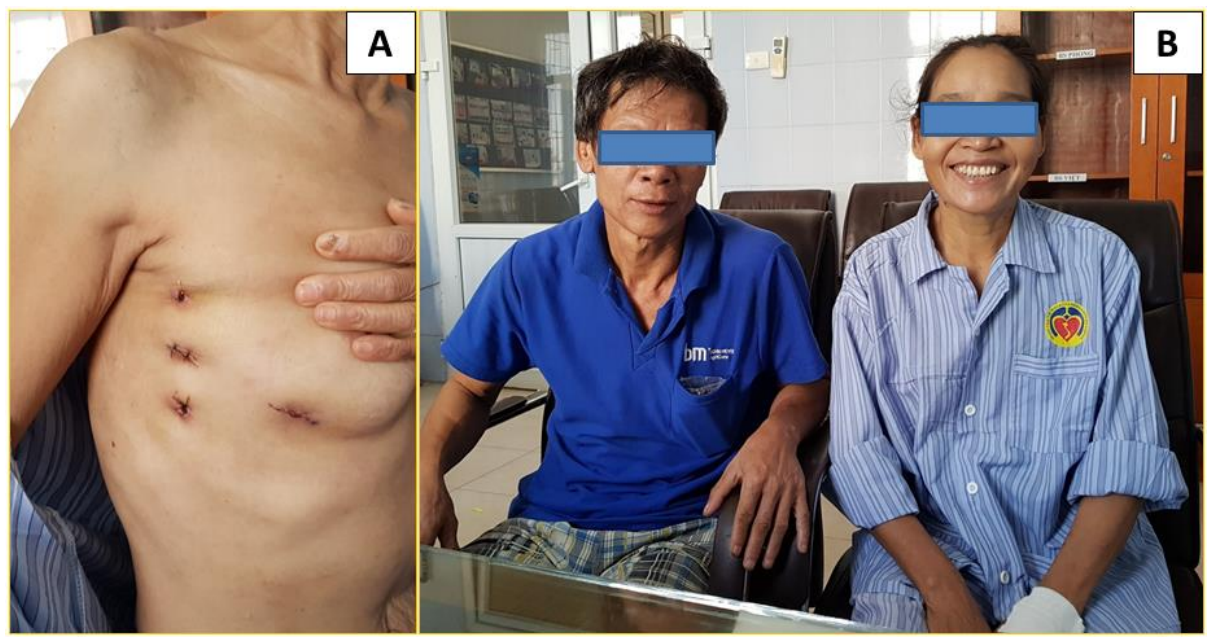

Hình 3, Tình trạng bệnh nhân trước thời điểm ra viện.

$\boldsymbol{A}$, sẹo mổ của phẫu thuật nội soi toàn bộ; $\boldsymbol{B}$, gia đình bệnh nhân hài lòng về kêt quả điều trị

\section{BÀN LUẬN}

Rung nhĩ là biến chứng thường gặp ở bệnh nhân TLN trưởng thành[1]. Tỉ lệ phát hiện rung nhĩ ở bệnh nhân TLN khác nhau tùy theo từng nghiên cứu và phương pháp chẩn đoán, dao động trong khoảng từ $15 \%$ đến $47 \%[2,5,6]$. Trong bệnh TLN, tuổi của bệnh nhân tại thời điểm can thiêp/ phẫu thuật> 40 tuổi, đường kính nhĩ trái > $45 \mathrm{~mm}$, mức độ hở VHL, mức độ hở VBL, và áp lực ĐMP cao được xác định là những yếu tố nguy cơ xuất hiện rung nhĩ trước mổ [5, 7-9].Trong nghiên cứu thực hiện năm 2013, Nyboe cùng cộng sự ghi nhận tỉ lệ rung nhĩ ở nhóm bệnh nhân TLN > 50 tuổi lên tới 47\% [6]. Bệnh nhân của chúng tôi có nhiều yếu tố nguy cơ của rung nhĩ: 54 tuổi, đường kính nhĩ trái $>45 \mathrm{~mm}$, hở $\mathrm{VBL}$ nhiều, và tăng áp lực ĐMP nặng. Mặc dù không khai thác được tiền sử về rung nhĩ, căn cứ vào những yếu tố nguy cơ của bệnh nhân này chúng tôi có thể dự đoán rằng tình trạng rung nhĩ của bệnh nhân có thể đã có nhiều năm.

Đóng TLN bằng can thiệp/ phẫu thuật được chứng minh là có vai trò chuyển nhịp từ rung nhĩ về nhịp xoang với thời gian theo dõi trung hạn $(<$ 5 năm), sau 5 năm hiệu quả này giảm dần và có thể xuất hiện rung nhĩ mới[6, 10]. Mặc dù vậy, hiện tượng này có tỉ lệ thấp, và chủ yếu gặp ở bệnh nhân trẻ tuổi, rung nhĩ mới xuất hiện $[3,11]$. Bệnh nhân của chúng tôi tất nhiên không xảy ra hiện tượng chuyển nhịp sau mổ.

Murphy cùng cộng sự (1990) chỉ ra rằng $22 \%$ trường hợp tử vong muộn ở bệnh nhân TLN là do nhồi máu não [12]. Bệnh nhân TLN có nguy cơ bị nhồi máu não cao hơn ngay cả khi lỗ thông đã được đóng, tỉ lệ tử vong khi bị nhồi máu não cao hơn và tuồi bị nhồi máu não thấp hơn so với quần thể chung [2].

Nhồi máu não trước khi đóng kín lỗ thông chủ yếu do đảo chiều dòng shunt, rung nhĩ chỉ là nguyên nhân trong $5,4 \%$ - $28 \%$ trường hợp [1, 2]. Ngược lại, sau khi lỗ thông được đóng, rung nhĩ lại là nguyên nhân chính (chiếm 75-83\%) gây nhồi máu não $[2,3,9]$. Bệnh nhân của chúng tôi xuất hiện nhồi máu não trong giai đoạn hậu phẫu, ngay khi được kiểm soát bằng thuốc chống đông. Rất may bệnh nhân được chẩn đoán và can thiệp kịp thời không để lại hậu quả.

Im cùng cộng sự (2013) đã nêu lên đặc điểm về phẫu thuật Maze nhĩ phải và Maze hai nhĩ ở bệnh nhân TLN [13]. Uemura cùng cộng sự đưa ra khuyến cáo những bệnh nhân TLN kèm rung nhĩ nên được phẫu thuật Maze hai nhĩ kết hợp vá TLN [14]. Trong nghiên cứu thực hiện tại Mayo Clinic (2000), phẫu thuật Maze đã được chứng minh làm giảm tỉ lệ nhồi máu não và biến chứng chảy máu nguy hiểm liên quan tới thuốc chống đông so với nhóm chứng $(\mathrm{p}=0,04)$ [15]. Kosakai cùng cộng sự (2000) cho thấy phẫu thuật Maze là đáng tin cậy ở bệnh nhân TLN với tỉ lệ thành công trong khoảng thời gian theo dõi trung hạn là $68,2 \%$ [16]. Rất tiếc bệnh nhân của chúng tôi không được điều trị bằng phẫu thuật Maze. Hướng điều trị tiếp theo là chống đông dự phòng và kiểm soát nhịp thất. 


\section{KẾT LUẬN}

Rung nhĩ là biến chứng thường gặp ở bệnh nhân TLN trưởng thành, là nguyên nhân chủ yếu gây nhồi máu não và tử vong sau khi lỗ TLN đã được đóng. Phẫu thuật Maze hai nhĩ nên được kết hợp với vá TLN giúp thay đổi tiên lượng và chất lượng sống cho người bệnh sau mổ.

\section{TÀI LIẸU THAM KHẢO}

1. F. Berger, M. Vogel, O. Kretschmar và các cộng sự. (2005), "Arrhythmias in patients with surgically treated atrial septal defects", Swiss Med Wkly, 135(11-12), tr. 175-8.

2. C. Nyboe, M. S. Olsen, J. E. NielsenKudsk và các cộng sự. (2015), "Atrial fibrillation and stroke in adult patients with atrial septal defect and the long-term effect of closure", Heart, 101(9), tr. 706-11.

3. F. Berger, M. Vogel, A. Kramer và các cộng sự. (1999), "Incidence of atrial flutter/fibrillation in adults with atrial septal defect before and after surgery", Ann Thorac Surg, 68(1), tr. 75-8.

4. L. I. Bonchek, M. W. Burlingame, S. J. Worley và các cộng sự. (1993), "Cox/maze procedure for atrial septal defect with atrial fibrillation: management strategies", Ann Thorac Surg, 55(3), tr. 607-10.

5. J. M. Oliver, P. Gallego, A. Gonzalez và các cộng sự. (2002), "Predisposing conditions for atrial fibrillation in atrial septal defect with and without operative closure", Am J Cardiol, 89(1), tr. 39-43.

6. C. Nyboe, M. Fenger-Gron, J. E. Nielsen-Kudsk và các cộng sự. (2013), "Closure of secundum atrial septal defects in the adult and elderly patients", Eur J Cardiothorac Surg, 43(4), tr. 752-7.

7. J. Wi, J. Y. Choi, J. M. Shim và các cộng sự. (2013), "Fate of preoperative atrial fibrillation after correction of atrial septal defect", Circ J, 77(1), tr. 109-15.

8. W. L. Henry, J. Morganroth, A. S. Pearlman và các cộng sự. (1976), "Relation between echocardiographically determined left atrial size and atrial fibrillation", Circulation, 53(2), tr. 273-9.

9. M. A. Gatzoulis, M. A. Freeman, S. C. Siu và các cộng sự. (1999), "Atrial arrhythmia after surgical closure of atrial septal defects in adults", $N$ Engl J Med, 340(11), tr. 839-46.

10. J. A. Vecht, S. Saso, C. Rao và các cộng sự. (2010), "Atrial septal defect closure is associated with a reduced prevalence of atrial tachyarrhythmia in the short to medium term: a systematic review and meta-analysis", Heart, 96(22), tr. 1789-97.

11. C. K. Silversides, S. C. Siu, P. R. McLaughlin và các cộng sự. (2004), "Symptomatic atrial arrhythmias and transcatheter closure of atrial septal defects in adult patients", Heart (British Cardiac Society), 90(10), tr. 1194-1198.

12. J. G. Murphy, B. J. Gersh, M. D. McGoon và các cộng sự. (1990), "Long-term outcome after surgical repair of isolated atrial septal defect. Follow-up at 27 to 32 years", N Engl J Med, 323(24), tr. 1645-50.

13. Y. M. Im, J. B. Kim, S. C. Yun và các cộng sự. (2013), "Arrhythmia surgery for atrial fibrillation associated with atrial septal defect: right-sided maze versus biatrial maze", J Thorac Cardiovasc Surg, 145(3), tr. 648-54, 655 e1; discussion 654-5.

14. H. Uemura (2016), "Surgical aspects of atrial arrhythmia : Right atrial ablation and antiarrhythmic surgery in congenital heart disease", Herzschrittmacherther Elektrophysiol, 27(2), tr.137-42.

15. H. V. Schaff, J. A. Dearani, R. C. Daly và các cộng sự. (2000), "Cox-Maze procedure for atrial fibrillation: Mayo Clinic experience", Semin Thorac Cardiovasc Surg, 12(1), tr. 30-7.

16. Y. Kosakai (2000), "Treatment of atrial fibrillation using the Maze procedure: the Japanese experience", Semin Thorac Cardiovasc Surg, 12(1), tr. 44-52. 